\title{
Editorial
}

\section{Sustainable Energy Development under Climate Change}

\author{
Chih-Chun Kung ${ }^{1, *}$ and Bruce A. McCarl ${ }^{2}$ \\ 1 Institute for Advanced Studies in Finance and Economics at Hubei University of Economics, \\ Wuhan 430205, China \\ 2 Department of Agricultural Economics, Texas A\&M University, College Station, TX 77843-2124, USA; \\ mccarl@tamu.edu \\ * Correspondence: cckung78@hotmail.com or cckung78@jxufe.edu.cn
}

Received: 11 September 2018; Accepted: 12 September 2018; Published: 13 September 2018

check for updates

\begin{abstract}
The world faces unprecedented threats from climate change and increasing variability, which severely impacts human society and the natural environment. To reduce future climate change and ensure our economies can grow in a sustainable way, sustainable energy development is considered to be an effective approach. In this context, sustainable energy development involves augmenting our energy supplies and managing demands in a fashion that societal energy needs are met with a minimal effect on greenhouse gas emissions and a nominal resultant contribution to future climate change. In this Special Issue, research papers focus on the role of sustainable energy development (while addressing important dimensions of sustainability), which mandates an inter-disciplinary perspective in all articles. We collected 11 such papers that have analyzed a broad array of topics related to bioenergy, wind power, industrial innovation, and climate change mitigation. These papers show the varied application of renewable energy and climate change energy responses, while providing meaningful decision-making information and policy implications.
\end{abstract}

Keywords: clean energy; climate change mitigation; quantitative analysis; sustainable development

\section{Introduction}

The 2007 report of Intergovernmental Panel on Climate Change (IPCC) [1] shows that the average temperature has increased by approximately $0.5{ }^{\circ} \mathrm{C}$ in the 20th century and can further rise by $1.4{ }^{\circ} \mathrm{C}$ to $5.8^{\circ} \mathrm{C}$ by the end of the 21 st century. As greenhouse gas emissions continue to increase, many undesirable outcomes such as sea level rise, diminished land productivity, desertification, and increased possibility of extreme events will inevitably occur [2]. Thus, exploring clean, sustainable, and renewable energy sources that emit less GHGs per unit energy is an urgent task facing all nations.

Various renewable energy techniques such as bioenergy, wind power, and solar energy have been applied and widely studied [3-7]; however, in order to justify the expansion of any renewable fuel, their full value must be recognized and their economic and environmental consequences-emission reduction, energy security, social development, and wealth distribution-must be comprehensively analyzed in the face of global climate change. This special issue showcases 11 articles that address these issues.

\section{Contributions of Collections}

In the first article, Zhang et al. [8] analyze the trade-offs between the economic and environmental benefits of alternative forms of a forest biomass power generation supply chain using a multi-objective linear programming model (MLP). The authors find that: the utilization of sandy shrubs can improve bioenergy production at a lower cost, and a significant amount of $\mathrm{CO}_{2}$ emissions can be sequestered. 
They also conduct a sensitivity analysis to examine the supply chain design and operating cost consequences of factors such as average transportation distance and unit chipping cost. They show that transportation and chipping play an important role in the design and scope of the supply chain.

The second paper by Wang et al. [9] applies a global non-radial directional distance function to estimate the performance of industrial green development (PIGD) in China from 2003-2015. The authors show that a rising trend in PIGD exists at the city level, but most cities failed to efficiently use resources such as energy and labor in industrial production. The authors indicate that China's green development may help mitigate climate change, but they also point out that a more efficient use of environmental management investment funds are needed to encourage the use of renewable energy in the industrial sector.

In the following paper, Lim et al. [10] aims to reveal how climatic conditions and building design alternatives influence the energy consumption of buildings in Seoul, Tokyo, and Hong Kong, both as an impact of climate change projections, and as a means to prioritize energy-saving potential alternatives under future climate change. The authors find that across these cities, the amount of cooling degree-hours needed to maintain comfort sharply increases. However, abatement measures are possible, where the authors indicate that a combined application of adaptive comfort control, nighttime ventilation, and occupancy-based equipment could reduce cooling energy consumption by up to $28 \%$. They also show how integrated photovoltaic systems can provide important benefits and that only simple modifications of occupant behavior are required to achieve cost-effective solutions.

The fourth study by Ma et al. [11] analyzes the contributions of various factors to the national growth of energy-related $\mathrm{CO}_{2}$ emissions. The primary energy quantity converted and carbon dioxide emission factors are identified as key parameters. The authors show that the reduction of energy intensity, the improvement of energy supply efficiency, and the introduction of non-fossil fuels are potentially helpful in climate change mitigation and sustainable development.

The main theme of the fifth paper by Ma et al. [12] focuses on the accuracies of past renewable energy projections in the US. The authors point out that policymakers in the US rely on energy forecasts to draft and implement cost-minimizing, efficient and realistic policies, but the inaccuracies in past projections have been high. The authors explore reasons for such inaccuracies and inconsistencies identifying massive assumptions and modeling flaws. In turn, they argue that a machine learning forecasting algorithm, devoid of massive independent variables and assumptions, could improve performance. The authors find that, relative to the 2008 Energy Information Administration's Annual Energy Outlook, their proposed technique presents an enormous improvement up to 138.26-fold on renewable energy consumption from biomass (REC-BMs) and 24.67-fold on hydroelectric power energy demand (HE-EC). The authors also show that the increase in accuracy is replicable in other regions.

The sixth paper by Zhang et al. [13] quantitatively investigates the cause-effect relationships among mechanisms of contractor-designer alliance in international hydropower EngineeringProcurement-Construction (EPC) projects. This indicates that allowing the building of interdisciplinary linkages between the areas of alliance, design management, and performance of inter-firm cooperation functions would allow one to achieve superior design and sustainability outcomes of hydropower EPC projects.

In the next paper, Lee et al. [14] examines the effect of using water spray systems as a cooling alternative in urban environments. The authors demonstrate that water spray systems have a higher cooling performance in drier conditions. They also show that using large water droplets can increase cooling effectiveness and that improved water spray system can ultimately reduce the need for cooling via fossil and non-fossil (including renewable energy) fuels, contributing to climate change mitigation.

The central theme of the Guo et al. paper [15] involves the mismatch between emission reductions and the resulting changes in regional air quality. The authors propose an ecology- and security-constrained unit commitment (Eco-SCUC) model that integrates both air quality intensity (API) and stochastic wind power constraints to improve emissions modeling. They show that the Eco-SCUC suggests cost-effective means to improve air quality in densely-populated regions, which in 
turn would reduce residents' exposure to severe air pollution. The authors also estimate the benefits of wind power, providing potentially useful information on renewable energy production and climate change mitigation to policy makers.

The next paper by DeCicco [16] focuses on estimation of the net emission reductions when using biofuels and how the estimates vary due to methodological uncertainties. The author compares the lifecycle assessment (LCA) and annual basis carbon (ABC) methods. This study highlights the importance of estimating the baseline carbon uptake, which can affect the sign of the results. The author suggests that in order to more accurately estimate the GHG offset effectiveness of biofuel production, further methodological work, program-scale model development, empirical re-analysis, and reconsideration of existing public policies and research priorities will be needed.

The tenth paper by Konopka et al. [17] aims to evaluate the accuracy of wind energy development potential. The authors test the two wind models under two micrometeorological models (WAsP (meso-) and ENVI-met). They indicate that it is necessary to adapt the wind model to urban wind power assessments.

The main theme of the eleventh paper by Suárez et al. [18] considers how potential increases in temperature may alter cooling energy consumption, as well as a series of problems relating to health and comfort in southern Spain. The authors quantify the impact of future climate scenarios on energy demand, along with effects on indoor temperature and consider different passive conditioning strategies. The authors suggest that envelope treatment, solar gain protection, and night-time natural ventilation can reduce energy demand and indoor temperatures, thus increasing energy efficiency, reducing energy consumption, and potentially reducing GHG emissions.

\section{Conclusions}

All the papers in this Special Issue provide insights on how sustainable energy can be used to address our energy future, while also reducing the impact of increased demands on climate change. Although the papers employ multiple and sometimes complex methods or techniques, the ultimate reason for this research is not the development of a complicated model, but an attempt to gain insight into approaches that jointly address energy and climate issues. The discourse is crucial in order to explain and distribute findings, motivate actions, and stimulate additional research on the issue.

Funding: The authors are thankful for the financial support of the National Science Foundation of China (41861042), that of the US (1739977), the Distinguished Young Scholar program of Jiangxi Province (20171BCB23047) and Texas AgriLife research using state and USDA AFRI funds that permitted us to invite, collect, process, and edit this special issue.

Conflicts of Interest: The authors declare no conflict of interest.

\section{References}

1. Intergovernmental Panel on Climate Change. Climate Change 2007: Impacts, Adaptation and Vulnerability; Cambridge University Press: Cambridge, UK, 2007.

2. Intergovernmental Panel on Climate Change. Climate Change 2013: The Physical Science Basis; Cambridge University Press: Cambridge, UK, 2014.

3. McCarl, B.A.; Adams, D.M.; Alig, R.J.; Chmelik, J.T. Analysis of biomass fueled electrical power plants: Implications in the agricultural and forestry sectors. Ann. Oper. Res. 2000, 94, 37-55. [CrossRef]

4. Karp, A.; Artaxo Netto, P.E.; Berndes, G.; Cantarella, H.; El-Lakany, H.; Estrada, T.E.M.D.; Van Sluys, M.A. Environmental and Climate Security. In Bioenergy \& Sustainability: Bridging the Gaps; Souza, G.M., Victoria, R.L., Joly, C.A., Verdade, L.M., Eds.; Scientific Committee on Problems of the Environment (SCOPE): São Paulo, Brazil, 2015.

5. Kaiser, H.M.; Riha, S.J.; Wilks, D.S.; Rossiter, D.G.; Sampath, R. A farm-level analysis of economic and agronomic impacts of gradual global warming. Am. J. Agric. Econ. 1993, 75, 387-398. [CrossRef]

6. Hennings, W.; Mischinger, S.; Linssen, J. Utilization of excess wind power in electric vehicles. Energy Policy 2013, 62, 139-144. [CrossRef] 
7. Kaldellis, J.K.; Zafirakis, D. The wind energy (r)evolution: A short review of a long history. Renew. Energy 2011, 36, 1887-1901. [CrossRef]

8. Zhang, M.; Wang, G.; Gao, Y.; Wang, Z.; Mi, F. Trade-Offs between Economic and Environmental Optimization of the Forest Biomass Generation Supply Chain in Inner Mongolia, China. Sustainability 2017, 9, 2030. [CrossRef]

9. Wang, W.; Xie, H.; Lu, F.; Zhang, X. Measuring the Performance of Industrial Green Development Using a Non-Radial Directional Distance Function Approach: A Case Study of Jiangxi Province in China. Sustainability 2017, 9, 1757. [CrossRef]

10. Lim, J.H.; Yun, G.Y. Cooling Energy Implications of Occupant Factor in Buildings under Climate Change. Sustainability 2017, 9, 2039. [CrossRef]

11. Ma, L.; Chong, C.; Zhang, X.; Liu, P.; Li, W.; Li, Z.; Ni, W. LMDI Decomposition of Energy-Related $\mathrm{CO}_{2}$ Emissions Based on Energy and $\mathrm{CO}_{2}$ Allocation Sankey Diagrams: The Method and an Application to China. Sustainability 2018, 10, 344. [CrossRef]

12. Ma, J.; Oppong, A.; Acheampong, K.N.; Abruquah, L.A. Forecasting Renewable Energy Consumption under Zero Assumptions. Sustainability 2018, 10, 576. [CrossRef]

13. Zhang, Q.; Tang, W.; Liu, J.; Duffiel, C.F.; Hui, F.K.P.; Zhang, L.; Zhang, W. Improving Design Performance by Alliance between Contractors and Designers in International Hydropower EPC Projects from the Perspective of Chinese Construction Companies. Sustainability 2018, 10, 1171. [CrossRef]

14. Lee, Y.C.; Chang, T.J.; Hsieh, C.I. A Numerical Study of the Temperature Reduction by Water Spray Systems within Urban Street Canyons. Sustainability 2018, 10, 1190. [CrossRef]

15. Guo, D.; Yu, J.; Ban, M. Security-Constrained Unit Commitment Considering Differentiated Regional Air Pollutant Intensity. Sustainability 2018, 10, 1433. [CrossRef]

16. DeCicco, J.M. Methodological Issues Regarding Biofuels and Carbon Uptake. Sustainability 2018, $10,1581$. [CrossRef]

17. Konopka, J.; Lopes, A.; Matzarakis, A. An Original Approach Combining CFD, Linearized Models, and Deformation of Trees for Urban Wind Power Assessment. Sustainability 2018, 10, 1915. [CrossRef]

18. Suárez, R.; Escandón, R.; López-Pérez, R.; León-Rodríguez, A.L.; Klein, T.; Silvester, S. Impact of Climate Change: Environmental Assessment of Passive Solutions in a Single-Family Home in Southern Spain. Sustainability 2018, 10, 2914. [CrossRef]

(C) 2018 by the authors. Licensee MDPI, Basel, Switzerland. This article is an open access article distributed under the terms and conditions of the Creative Commons Attribution (CC BY) license (http://creativecommons.org/licenses/by/4.0/). 